[0212-7199(2001) 18: 2; pp 88-89] ANALES DE MEDICINA INTERNA Copyright $\odot 2001$ ARAN EDICIONES, S.A.

AN. MED. INTERNA (Madrid) Vol. 18, N. ${ }^{\circ} 2$, pp. $88-89,2001$

\title{
Trombopenia asociada a esclerodermia localizada
}

\author{
P. RONDÓN, A. AGUILAR*, M. GALLEGO*
}

Servicio de Medicina Interna y *Dermatología. Hospital Severo Ochoa. Leganés. Madrid

\author{
THROMBOCYTOPENIA ASSOCIATED TO LOCALIZED SCLERO - \\ DERMA
}

\section{RESUMEN}

Presentamos dos pacientes con esclerodermia localizada que desarrollaron trombocitopenia. En uno de los casos se evidenció ANA y anticuerpos anti-DNA positivo. La aparición de trombocitopenia en esclerodermia localizada sugiere un mecanismo autoinmune, tanto por la respuesta a esteroides como por la existencia de autoanticuerpos. Esta posible asociación establece la necesidad de buscar alteraciones hematológicas, tanto en la esclerodermia sistémica, como en la localizada.

PALABRAS CLAVE: Trombocitopenia. Esclerodermia sistémica y localizada. Autoinmunidad.

\begin{abstract}
Two patients are reported with localized scleroderma who develo ped thrombocytopenia. One of these patients had a positive antinuclear antibody (ANA) and Anti-DNA antibodies tests. The ocurrence of throm bocytopenia in localized scleroderma suggests an autoimmune mecha nism, by the response to steroids and the presence of positive autoanti bodies.This possible association emphasizes the need to look for hematologic disorders in patients with systemic, as well as localized scleroderma.
\end{abstract}

KEY WORDS: Thrombocytopenia. Systemic and localized scleroderma. Autoimmunity.

Rondón P, Aguilar A, Gallego M. Trombopenia asociada a esclerodermia localizada. An Med Interna (Madrid) 2001; 18: 88-89

\section{INTRODUCCIÓN}

La esclerodermia localizada es una enfermedad crónica benigna, de etiología desconocida. Está caracterizada por áreas induradas de la piel, de color púrpura inicialmente, pero que pierden su coloración central, dejando un color nácar rodeado por el típico anillo de color lila (lilac ring) (1).

Las alteraciones hematológicas en la esclerodermia son poco frecuentes (2), generalmente se limitan a anemia moderada, aunque se ha descrito pancitopenia, aplasia de médula osea y anemia hemolítica (3).

La trombopenia aparece frecuentemente asociada al lupus eritematoso sistémico, en relación con mecanismos autoinmunes, pero es muy raro en casos de esclerodermia (4). Presentamos dos paciente con esclerodermia localizada y trombopenia.

\section{CASOS APORTADOS}

Caso 1: Mujer de 16 años con antecedentes de asma bronquial extrínseca en tratamiento con broncodilatadores inhalados. Desde hace siete años, nota la presencia de una placa hiperpigmentada a nivel de la región umbilical, precedida de prurito. La lesión inicial no mostró cambios desde que apareció, manteniéndose estable hasta el momento de su consulta en febrero de 1996. A los tres años del inicio del cuadro la paciente indica la existencia de una lesión similar a la primera, esta vez localizada en hemitórax derecho. Unos meses después aparece otra placa a nivel del dorso de la mano derecha, siempre manteniendo unas características clínicas similares a la primera. Refiere de forma ocasional la presencia de epistaxis.

En los controles analíticos periódicos se objetiva desde febrero de 1997 la existencia de trombopenia cuyas cifras han oscilado entre 85.000 y $111.000 / \mu \mathrm{L}$.

En la exploración física presenta: En región periumbilical una placa hiperpigmentada de $5,5 \mathrm{~cm}$ x $3,5 \mathrm{~cm}$, de bordes nítidos, superficie lisa y no infiltrada. En hemitórax anterior derecho presenta una placa similar a la anterior de $13 \mathrm{~cm}$ x $5 \mathrm{~cm}$. En el dorso de la mano derecha se objetiva una lesión hiperpigmentada de $3 \mathrm{~cm}$ de diámetro. El resto de la exploración fue normal. En las pruebas complementarias realizadas destaca: Hemograma: $\mathrm{Hb} 12,8 \mathrm{~g} / \mathrm{dl}$, Hto 38,4\%, Leuc 4.150/ $\mu \mathrm{L}$ (fórmula normal), Plaquetas: $85.000 / \mu \mathrm{L}$, VSG $11 \mathrm{~mm} 1$ hora; Coagulación normal; EEF sin alteraciones; Bioquímica: Glucosa, Urea, Creatinina, Ac. úrico, colesterol, triglicéridos, albúmina, bilirrubina, GOT, GPT, GGT, Fosfatasa alcalina dentro de límites

Trabajo aceptado: 27 de Mayo de 1999

Correspondencia: P. Rondón Fernández. Avd. María Moliner 26, portal 3, 2º B. 28919 Leganés (Madrid). 
normales; C3 y C4 dentro de límites normales; Orina normal; ANA positivo, patrón moteado a título 1/40; Ac anti DNA positivo débilmente; ENA negativo; Anticuerpos antiplaquetario negativos; Anticuerpos antifosfolípido negativo; Rx tórax sin alteraciones; Eco abdomen: sin alteraciones.

El estudio histológico es de esclerodermia localizada.

Caso 2: Mujer de 29 años, sin antecedentes de interés, que presenta en analítica de rutina una cifra de plaquetas de 95.000. Como clínica acompañante únicamente refiere epistaxis ocasionales. En la exploración física no se encontró ningún dato relevante. En las pruebas complementarias destacaba: Hemograma: Hb 11,1 g/dl, Hto $31,4 \%$, Leucocitos $6640 / \mu \mathrm{L}$ (fórmula normal), Plaquetas $95.000 / \mu \mathrm{L}$; Bioquímica: Glucosa, Creatinina, colesterol, triglicéridos, Proteínas totales, GOT, GPT, GGT y LDH, dentro de límites normales; Coagulación: normal; TSH normal; ANA negativo; ENA negativos; Serología a VHB, VHC, VIH negativos; C3, C4 dentro de límites normales; Anticuerpos antifosfolípido negativos; Ecografía abdominal: Pequeño hemangioma en segmento 6 hepático.

La paciente ha mantenido una cifra de plaquetas que han oscilado entre 55.000 y 95.000 .

Asintomática hasta seis meses antes que consulta por presentar una placa de coloración rosada, de crecimiento lento de aproximadamente $10 \times 7 \mathrm{~cm}$, en plano anterior torácico. Se realiza estudio histológico de dicha lesión, siendo compatible con esclerodermia locali zada.

\section{DISCUSIÓN}

En la esclerodermia localizada han sido documentadas alteraciones sistémicas, tales como artralgias o fenómeno de Raynaud, pero es raro encontrar una afectación visceral mayor (5). Los test de laboratorio han revelado la presencia de anticuerpos antinucleares y anticuerpos anti-DNA en un $40 \%$ y en un $50 \%$ de los casos respectivamente (1).

La asociación de trombopenia con esclerodermia sistémica fue descrita por primera vez en 1971 por Ivery y cols. (6). En un estudio retrospectivo de alteraciones hematológicas presentes en la esclerodermia sistémica, Frayha y cols. encuentran que de 180 pacientes, ocho presentaban trombopenia (2).

Por otro lado, en 1980, Neucks y cols. presentan dos casos de trombocitopenia en pacientes afectados de esclerodermia localizada (5).

En 1985, Puras y cols., presentan un caso de esclerodermia focal asociado a trombocitopenia, el único de la literatura nacional (7). Sin embargo revisados los datos presentados, consideramos que iría más a favor de que se tratara de un caso de esclerodermia sistémica.

La aparición de trombopenia en la esclerosis, tanto sistémica como localizada sostienen la hipótesis de que estas dos entidades clínicas tienen un origen común. En revisiones previas se ha constatado el aumento de la cifra de plaquetas tras tratamiento con corticoides sistémicos. Existen evidencias indirectas que apuntan a fenómenos autoinmunes como responsables de la trombocitopenia en pacientes con esclerodermia localizada, sugerido por la respuesta a esteroides y a la presencia de anticuerpos antinucleares. Sin embargo el mediador de este fenómeno inmune es desconocido $(4,5)$.

Se ha documentado en un paciente con morfea un título alto de anticuerpos antifibronectina. Dichos anticuerpos estimulan la liberación de serotonina desde las plaquetas, mediados por el receptor Fc, y son dependientes de la actividad de los complejos antígeno-anticuerpo sobre la superficie plaquetaria. Estos anticuerpos podrían ser de importancia patogénica en la esclerodermia (1).

El hallazgo de trombopenia en nuestros dos pacientes con esclerodermia localizada podría representar un hallazgo casual. Sin embargo permanece aún por dilucidar si es el resultado de un proceso autoinmune. En resumen esta posible asociación obliga a un seguimiento cuidadoso de un proceso, que por otro lado es benigno.

\section{Bibliografía}

1. Ghersetich I, Teofoli P, Benci M, Innocenti S, Lotti T. Localized Sclerodema. Clin Dermatol 1994; 12: 237-242.

2. Frayha R, Shulman E, Stevens B. Hematological abnormalities in Scleroderma: A study of 180 cases. Acta Haematol 1980; 64: 25-30.

3. Doyle J, Connolly S, Hoagland C. Hematologic disease in scleroderma syndromes. Acta Derm and Venereol 1985; 65: 521-525.

4. Leivovici V, Zlotogorski A, Kanner A, Shinar E. Generalized morphea and idiopathic Thrombocytopenia. J Am Acad Dermatol 1988; 18: 1194-1196.
5. Neucks S, Moore T, Lichtenstein J, Baldassare A, Weiss T. Localized escleroderma and idiopathic thrombocytopenia. J Rheumatol 1980; 7: 741-744.

6. very K, Hwang Y, Sheets R. Scleroderma associated with thrombocytopenia and Coombs-positive hemolytic anemia. Am J Med 1971; 51: 815817.

7. Puras A, Del Villar Sordo V, Ralla J. Púrpura trombopénica autoinmune asociada a esclerodermia [carta]. Rev Clín Esp 1985; 177: 241. 